\title{
Work experiences, resources, and beliefs among vulnerable subgroups of mental health care users
}

\author{
Mona Eklund $^{\mathrm{a}, 1, *}$, Jan-Åke Jansson $^{\mathrm{b}, 2}$, Lisa Eklund ${ }^{\mathrm{c}, 3}$, \\ Parvin Pooremamali $^{\mathrm{d}, 4}$ and A. Birgitta Gunnarsson ${ }^{\mathrm{e}, 5}$ \\ ${ }^{a}$ Department of Health Sciences, Lund University, Lund, Sweden \\ ${ }^{\mathrm{b}}$ Department of Psychology and Department of Health Sciences, Lund University, Lund, Sweden \\ ${ }^{\mathrm{c}}$ Department of Sociology, Lund University, Lund, Sweden \\ ${ }^{\mathrm{d}}$ Department of Community Medicine and Rehabilitation, Occupational Therapy, Umeå University, Umeå, \\ Sweden \\ ${ }^{\mathrm{e}}$ Department of Research and Development, Region Kronoberg, Växjö, Sweden and Department of Clinical \\ Neuroscience and Rehabilitation, University of Gothenburg, Sweden
}

Received 3 March 2020

Accepted 5 November 2020

\begin{abstract}
.
BACKGROUND: People with mental illness may have difficulties related to work and employment, especially if they experience additional difficult life situations.

OBJECTIVE: To explore how subgroups with mental illness and additional adversities perceived their situation with respect to work and employment prospects.

METHODS: Three subgroups were included, exposed to an additional difficult life situation: i) psychosis interrupting their career development at young age $(n=46)$, ii) having a history of substance use disorder (SUD) (=57) or iii) having recently immigrated $(n=39)$. They responded to questionnaires addressing sociodemographics, work-related factors, everyday activity, and well-being. A professional assessed their level of functioning and symptom severity.

RESULTS: The young people with psychosis had a low education level, little work experience, the poorest worker role resources, and a low level of functioning, but a high quality of life. The SUD group had the fewest work experiences, were the least satisfied with work experiences, and had the lowest activity level, but had the least severe psychiatric symptoms. The immigrant group had severe psychiatric symptoms, but high ratings on work experiences, work resources, and activity level.

CONCLUSIONS: Each group presented unique assets and limitations pertaining to work and employment, suggesting that they also needed unique support measures.
\end{abstract}

Keywords: Psychosis, substance use disorder, immigrant, quality of life, satisfaction

\footnotetext{
${ }^{1}$ Mona Eklund ORCID ID: 0000-0002-0136-3079

${ }^{2}$ Jan-Åke Jansson ORCID ID: 0000-0002-6972-4686

${ }^{3}$ Lisa Eklund ORCID ID: 0000-0003-2276-2172

${ }^{4}$ Parvin Pooremamali ORCID ID: 0000-0002-0890-6793

${ }^{5}$ A Birgitta Gunnarsson ORCID ID: 0000-0002-6976-5154
}

*Address for correspondence: Mona Eklund Department of Health Sciences Lund University P. O. Box 157 SE-22100 Lund, Sweden. Tel.: +4670 537 9922; E-mail: mona.eklund@med.lu.se. 


\section{Introduction}

Many individuals who have a mental illness have difficulties in leading an active and satisfying everyday life that includes work [1]; and, those who do have employment tend to have jobs with poor psychosocial quality [2]. Laws [3] suggested that work among users of mental health care may be partly about living with and recovering from mental illness, partly about service-user production, which includes a variety of market and semi-market activities. The current study addressed work in the latter sense, and the intention was to shed light on mental health care users' experiences of and beliefs in open-market employment, including semi-market activities that they regard as "work". Methods have been developed to support people with mental illness who aspire to work in service-user production. Supported employment (SE), for example, is a highly appreciated [4] and effective $[1,5]$ form of assistance towards greater work capacity and participation. SE does not appeal to every person in the target group, however, and not all of those who take part in SE attain the target of open-market employment [1]. Although SE may be regarded as an evidence-based work rehabilitation method, there is still a need for a variety of support measures oriented towards work and employment, and possibly also for tailoring methods that acknowledge the needs that may be specific to different groups of people with mental illness.

Work is particularly susceptible to the combined effects of various stigma [6]. Extended knowledge is thus required about various subgroups of people with mental illness and their situation regarding workrelated factors, such as how they view their work capacity, how they envisage a future worker role, and if such perceptions are shared or differ between subgroups with various additional potentially stigmatizing characteristics. Stigma is defined here as a complex of difficulties shaped by prejudice, negative attitudes, and excluding or avoiding behaviours, often based on ignorance [7]. People can be exposed to stigma for a variety of reasons, such as mental illness, different types of disability, poverty, and ethnic origin.

Young people with psychosis are an example of a group at risk for multiple difficulties. It has been broadly recognized that they are at great risk of being marginalized in relation to the employment market and participation in society, since they generally develop their illness at an age where young people start their work careers $[8,9]$. Service users representing this group have often reported low levels of self-confidence and self-esteem, perceived stigma, treatment issues, and difficulties in identifying and achieving goals as some of their issues in relation to work [10]. Research has shown, however, that young people with psychosis, who received extensive psychosocial support for five years and were cautiously monitored regarding antipsychotic medication, showed good early recovery and good employment outcome after 13 years [11]. People with substance use disorder (SUD) form another vulnerable group [12]. Research indicates that concurrent alcohol use disorder prolongs the duration of the mental illness and leads to a deterioration in treatment outcomes [13]. It is also widely acknowledged that a combination of SUD and mental illness entails difficulties finding and retaining employment, while first-person accounts from this group indicate they could benefit from support based on SE principles [14]. A third group in need of specific attention because of a risk of stigma are people with mental illness who are immigrants in a new societal and cultural context [15]. For example, users of mental health services who originate from the Middle East seek care less frequently than Swedish-born citizens and their expectations on care and support may differ from those of the professionals working in mental health care [16]. They also have particular difficulties in finding a meaningful work-related activity [17]. All three groups - the young with psychosis, those with a history of SUD, and recent immigrants - may be seen as being vulnerable among the vulnerable, where a second disadvantage adds to that of mental illness, and they receive great attention in media and policy debates. They were therefore the focus in the current study. As indicated above, research has addressed some of their issues related to work and employment, but to the best of our knowledge, no studies seem to have attempted to compare vulnerable groups such as these in terms of work, employment, and related factors.

Work and employment among vulnerable groups should not be seen in isolation from other activities people perform in everyday life. Meaningful everyday activities, such as stimulating leisure, social activities, and caring for one's home and one's health, have been found to be satisfying and a good substitute for employment [18] and correspond to what Laws [3] terms as recovery work. Moreover, gender may play a role in relation to work and employment [19]. Research shows that former work experiences among people with mental illness align with traditional 
gendered patterns for both women and men [20], and so do productive activities provided in activity centres for people with mental illness [21, 22].

\subsection{Aim}

The study aim was to explore how three vulnerable groups of people with mental illness experiencing additional difficulties perceived their situation with respect to work and employment prospects, everyday activity, well-being, and level of psychosocial functioning and symptom severity. The focus was on both similarities and differences in these respects, and the three selected additional life situations were i) an interruption of their career development at a young age due to psychosis, ii) having a history of SUD, or iii) having recently immigrated to Sweden. Part of the aim was to investigate the importance of age and sex, since age was a characteristic of one of the groups and the study included a gender perspective.

\section{Methods}

This cross-sectional study was performed in Sweden, where the three types of additional difficult life situations in focus are of high relevance and are often debated in both the societal discourse and in discussions and policies pertaining to the health care and support systems. This was the rationale for selecting these three target groups. The Regional Ethical Review Board at Lund University approved the study, Reg. Nos. 2015/357 and 2017/137.

\subsection{Selection of participants}

A power analysis indicated that 60 participants in each subgroup was sufficient to detect a difference on the SDO instrument (see below) of 0.5 with $80 \%$ power at $p<0.05$. All three groups were convenience samples sought in regions near the institutions to which the researchers were affiliated. Managers of mental health care units admitting young people with psychosis in seven towns were approached and asked if they were willing to participate in the study; six of them agreed. Young age was defined as the interval between 18 and 30 years. Regarding the sample with a history of substance use disorder (SUD), contact was established with a major city in the area. The manager of the social services in that city was willing to assist in realizing the study aims and was able to recruit a sufficient number of participants who fulfilled the criteria of both having a history of SUD and a mental illness. Some were currently abstinent while others had ongoing misuse of alcohol and/or drugs. The sample who had recently immigrated to Sweden and had a mental illness were sought at a PTSD (post-traumatic stress syndrome) center in the region's largest city. The center offered mandatory lessons in Swedish and a variety of other optional activities, such as gardening, social skills training, health promotion, and learning how to use computers. A staff member was contracted in each of these settings and served as a link between prospective participants and the research team. This staff member provided written and oral information about the project to prospective participants. Those who were eligible were invited to take part in the study and those who agreed to participate signed their informed consent. The staff member then facilitated individual appointments between each participant and a research assistant or one of the researchers, who performed the data collection in either Swedish, Arabic, Farsi, Dari or Pashto. Those who performed the data collection had backgrounds as an occupational therapist or a psychologist in mental health care and had received training in using the instruments.

The characteristics of the participants in the three groups are presented in Table 1, which shows that they were similar on gender distribution, with about $30 \%$ women. The young with psychosis were younger than the other two groups for natural reasons. Those with a history of SUD and the group of recent immigrants did not differ in age, but had very dissimilar life circumstances regarding type of household and whether they had children or not. The group with a history of SUD were mainly single and approximately 50\% had children, whereas $80 \%$ of respondents in the immigrant group were married or cohabiting, and the same proportion had children. The proportion of foreign-born participants, which was 100\% among the immigrants, was considerably smaller in the other two groups. The foreign-born in the group of young people with psychosis originated from Asian, Balkan and North American countries, whereas those in the group with a history of SUD came from European countries. In the group of recent immigrants, $59 \%$ had fled from Syria and the rest came from other Middle Eastern countries. Diagnoses differed per definition between the groups, with psychosis prevailing in the young group and PTSD in the immigrant group, but as seen in Table 1 there was some variation within the groups. A neuropsychiatric disorder was the most frequent diagnosis in the group with a history of SUD, 
Table 1

Characteristics of the participants in the three subgroups

\begin{tabular}{|c|c|c|c|c|}
\hline & $\begin{array}{l}\text { Group 1 } \\
\text { Young with } \\
\text { psychosis } \\
\mathrm{N}=46\end{array}$ & $\begin{array}{c}\text { Group2 } \\
\text { Substance } \\
\text { use } \\
\mathrm{N}=57\end{array}$ & $\begin{array}{c}\text { Group } 3 \\
\text { Recent } \\
\text { immigrant } \\
\mathrm{N}=39\end{array}$ & $P$-value ${ }^{1)}$ \\
\hline Age; mean (SD) years & $26(3)$ & $43(9.7)$ & $41(9.5)$ & $<0.001$ \\
\hline Gender; \% women/men/non-binary & $30 / 67 / 2$ & $29 / 71$ & $33 / 67$ & Ns. \\
\hline Foreign-born; \% & 22 & 10 & 100 & $<0.001$ \\
\hline Type of household; \% & & & & $<0.001$ \\
\hline Single & 52 & 89 & 18 & \\
\hline Married or cohabiting & 17 & 9 & 80 & \\
\hline Living with family/friends & 30 & 2 & 3 & \\
\hline Having children; $\%$ & 15 & 49 & 80 & $<0.001$ \\
\hline Having a friend; $\%$ & 96 & 88 & 72 & 0.001 \\
\hline Highest education; \% & & & & $<0.001$ \\
\hline Non-completed 9-year school & 2 & 5 & 28 & \\
\hline Completed 9-year school & 39 & 46 & 49 & \\
\hline Completed high school & 59 & 40 & 8 & \\
\hline Completed university degree & - & 9 & 15 & \\
\hline Self-reported diagnosis; $\%$ & & & & $<0.001$ \\
\hline Psychosis & 89 & 4 & 0 & \\
\hline Neuropsychiatric disorder & 2 & 35 & 0 & \\
\hline Mood/anxiety disorder & 2 & 14 & 16 & \\
\hline PTSD & 0 & 5 & 83 & \\
\hline Other & 7 & $42^{1)}$ & 0 & \\
\hline
\end{tabular}

1) $40 \%$ in the group with a history of SUD did not report a diagnosis, or reported they did not have one.

and a large proportion of this group did not report a mental illness other than SUD. None of the young with psychosis had completed a university education, but $59 \%$ had completed high school or the equivalent. The highest level of education for $77 \%$ of the recent immigrants was nine years of schooling or less. The group with a history of SUD had the highest educational level.

\subsection{Data collection}

A background questionnaire, which addressed sociodemographic factors such as age, gender, civil status, children, housing, education, and country of origin, was devised for this study. An additional question asked about self-reported diagnosis. The diagnoses were then coded by the research team according to the ICD classification [23]. A similar procedure has previously been found valid [24]. Furthermore, the following instruments were used. The data collection was completed in 2019.

\subsubsection{Worker role aspects}

The Worker Role Self-Rating (WRS) instrument $[25,26]$ was used to assess two aspects - beliefs in a future worker role and having resources for engaging in a worker role - which form two psychometrically sound subscales of the WRS [26]. A 16-item version with a five-step response scale (1-5) was used, where a higher rating indicates stronger beliefs in the two worker role aspects. Both subscales have shown adequate reliability and construct validity [26].

\subsubsection{Satisfaction with everyday activities}

Satisfaction with Daily Occupations (SDO) [27] is an interview-based questionnaire addressing various aspects of everyday activities [27]. A 14-item version, where each item addresses a particular activity, pertaining to work/studies, leisure, home maintenance and self-care, was used for this study. The SDO generates two subscales, one of which is the level of activity (number of activities performed) and the other satisfaction with one's everyday activities, irrespective of whether the activities are currently performed or not. The respondent rates his/her satisfaction on a seven-point scale (1-7) where a higher rating indicates greater satisfaction. The two first SDO items, concerning having worked or studied during the past two months, and being employed or admitted to an education during the past two months, were used to create two variables reflecting the respondents' current situation in terms of work/studies. One concerned having had recent experiences of work/studies and the other concerned satisfaction with the situation pertaining to work/studies, whether the respondent had been involved in work/studies or not. The SDO 
has shown adequate reliability, validity and test-retest stability [28, 29].

\subsubsection{Life satisfaction and quality of life}

The Manchester Short Assessment of Quality of Life (MANSA) [30] has 12 items addressing life satisfaction. The first item targets general life satisfaction. The other 11 concern satisfaction within a number of life domains, such as work, housing, family, friends, intimate relations, personal security and health. Each item is rated on a seven-point scale (1-7). A higher rating signifies greater satisfaction, and the 11 items are summarized into a quality of life index. Both the original version [30] and the Swedish version [31], used in the present study, have shown adequate psychometric properties in terms of reliability and validity.

\subsubsection{Global functioning}

Research assistants with an occupational therapy or psychology background performed the assessment of functioning, using the Global Assessment of Functioning Scale (GAF) [32]. Two GAF ratings are made, one addressing symptom severity and the other the level of psychosocial functioning. Both ratings are made on an interval scale ranging from 0 to 100, and higher scores signify better functioning. Scores of 80 and above indicate good mental health. Only a short training of the raters is required to obtain reliable scores [33]. The research assistants performing the ratings in the current study received training by watching fictional but realistic video cases and then calibrating their rating with a skilled and experienced GAF rater. GAF is considered reliable and valid [34] and is widely used.

\subsection{Data analyses}

$T$-test or one-way ANOVA with Bonferroni posthoc test was used for analyses based on age. Non-parametric statistics were used for all other variables since the instruments used generated ordinal scales [35]. Group differences were analyzed by the Kruskal-Wallis test (for several independent samples) or the Mann-Whitney test (for two independent samples). To test for possible linear trends among the three groups, i.e. if there was a rank order among the groups where each differed from the other two, the Jonckheere-Terpstra test was employed. Spearman correlations were used to analyze associations between variables. In order to estimate the strength of associations, the limits proposed by Cohen [36] were applied; correlations $<0.30$ are weak, $0.30-0.50$
Table 2

Correlations between age and the variables reflecting worker role, everyday activities, well-being, and functioning, based on the sample as a whole $(\mathrm{N}=142)$

\begin{tabular}{ll}
\hline & Age \\
\hline Work experience & $\mathrm{r}_{\mathrm{s}}=-0.104 ; \mathrm{ns}$. \\
Satisfaction with work experience & $\mathrm{r}_{\mathrm{s}}=-0.115 ; \mathrm{ns}$. \\
Future worker role & $\mathrm{r}_{\mathrm{s}}=-0.117 ; \mathrm{ns}$. \\
Work resources & $\mathrm{r}_{\mathrm{s}}=0.248 ; p<0.003$ \\
Satisfaction with everyday activities & $\mathrm{r}_{\mathrm{s}}=-0.197 ; p=0.021$ \\
Activity level & $\mathrm{r}_{\mathrm{s}}=0.088 ; \mathrm{ns}$. \\
General life satisfaction & $\mathrm{r}_{\mathrm{s}}=-0.083 ; \mathrm{ns}$. \\
Quality of life index & $\mathrm{r}_{\mathrm{s}}=-0.230 ; p=0.007$ \\
Psychosocial functioning & $\mathrm{r}_{\mathrm{s}}=0.332 ; p<0.001$ \\
Symptom severity & $\mathrm{r}_{\mathrm{s}}=0.148 ; \mathrm{ns}$. \\
\hline
\end{tabular}

are moderate, and $>0.50$ are strong. $P$-values $<0.05$ were regarded as statistically significant. The software used was IBM SPSS version 26 [37].

\section{Results}

\subsection{Relevance of sociodemographic factors}

Age was related to a few of the factors under study, as seen in Table 2. The findings based on the sample as a whole indicate that older age was associated with higher ratings of resources for having a worker role, as well as higher interviewer-ratings of level of psychosocial functioning. On the other hand, younger age was related to higher ratings of satisfaction with everyday activities and the quality of life index. This influence of age thus makes the group consisting of young people with psychosis disadvantaged with respect to resources for having a worker role and psychosocial functioning, but advantaged in relation to satisfaction with everyday activities and quality of life. All statistically significant correlations were weak, or in the lower end of moderate, as displayed in Table 2. Work experience, satisfaction with work experience, beliefs in a future worker role, activity level, general life satisfaction and severity of symptoms were not related to age. Analyses of differences between women and men indicated no statistically significant associations. This suggests that the selected variables pertaining to work experience, the worker role, everyday activities, well-being, and level of functioning were not gendered.

\subsection{Recent experiences of work/studies}

Further analyses, presented in Table 3, included comparisons between the three vulnerable groups. 
Table 3

Factors related to the worker role, everyday activities, well-being and level of functioning in the three groups

\begin{tabular}{|c|c|c|c|c|c|}
\hline & $\begin{array}{c}\text { Group 1 } \\
\text { Young with } \\
\text { psychosis }\end{array}$ & $\begin{array}{c}\text { Group } 2 \\
\text { Substance } \\
\text { use }\end{array}$ & $\begin{array}{c}\text { Group } 3 \\
\text { Recent } \\
\text { immigrant }\end{array}$ & $P$-value ${ }^{1)}$ & $\begin{array}{l}\text { Trend for } \\
\text { group } \\
\text { difference }^{2)}\end{array}$ \\
\hline Work experience; mean (SD) (possible range 0-2) & $1.0(0.9)$ & $0.2(0.5)$ & $1.9(0.2)$ & $<0.001$ & $3>1>2^{3)} \mathrm{p}<0.001$ \\
\hline $\begin{array}{l}\text { Satisfaction with work experience; mean (SD) } \\
\text { (possible range } 2-14 \text { ) }\end{array}$ & $9.3(3.2)$ & $6.9(3.7)$ & $10.7(3.4)$ & $<0.001$ & $1>2 ; 3>2$ \\
\hline $\begin{array}{l}\text { Future worker role; mean (SD) (possible range } \\
16-80 \text { ) }\end{array}$ & $30.0(6)$ & $28.9(6.7)$ & $28.5(5.2)$ & ns. & \\
\hline Work resources; mean (SD) (possible range 16-80) & $28.0(5.6)$ & $29.9(5.1)$ & $30.3(4.7)$ & 0.053 & $3>2>1^{3)} \mathrm{P}=0.020$ \\
\hline $\begin{array}{l}\text { Satisfaction with everyday activities; mean (SD) } \\
\text { (possible range 14-98) }\end{array}$ & $70.5(11.5)$ & $60.7(18.9)$ & $63.7(15.1)$ & 0.017 & $1>2 ; 1>3$ \\
\hline Activity level; mean (SD) (possible range 0-14) & $8.5(2.2)$ & $7.4(2.2)$ & $10.6(2.5)$ & $<0.001$ & $3>1>2^{3)} \mathrm{p}=0.001$ \\
\hline $\begin{array}{l}\text { General life satisfaction; mean (SD) (possible range } \\
1-7 \text { ) }\end{array}$ & $4.5(1.5)$ & $4.0(1.9)$ & $3.9(1.7)$ & ns. & \\
\hline $\begin{array}{l}\text { Quality of life index; mean (SD) (possible range } \\
\text { 11-77) }\end{array}$ & $40.0(10.4)$ & $32.4(9.2)$ & $32.6(6.8)$ & $<0.001$ & $1>2>3^{3)} \mathrm{p}=0.009$ \\
\hline $\begin{array}{l}\text { Psychosocial functioning; mean (SD) (possible } \\
\text { range } 0-100 \text { ) }\end{array}$ & $56.9(9.4)$ & $60.7(9.6)$ & $63.3(9.2)$ & 0.001 & $3>2>1^{3)} \mathrm{p}<0.001$ \\
\hline $\begin{array}{l}\text { Symptom severity; mean (SD) (possible range } \\
0-100)\end{array}$ & $57.7(9)$ & $62.0(6.2)$ & $56.6(7.9)$ & $<0.001$ & $2>1 ; 2>3$ \\
\hline
\end{tabular}

Note. Since the analyses of group differences were based on non-parametric methods and ranks, the findings regarding linear trends do not always align with the mean values, for example for quality of life. ${ }^{1)}$ Based on the Kruskal-Wallis test. ${ }^{2)}$ The digits refer to the group numbering. ${ }^{3)}$ Linear trend based on the Jonckheere-Terpstra test.

There was a linear trend regarding work/study experience, in terms of having had employment or having studied during the past two months. The group with recent immigrants scored the highest, the young with psychosis scored in-between, and the group with a history of substance use scored the lowest. A similar pattern was found for satisfaction with the work/study situation, with the substance use group scoring lowest, but in this case there was no statistically significant difference between the other two groups.

\subsection{Perceptions of the worker role}

There was no difference between the groups in terms of beliefs in a future worker role (see Table 3). The groups differed on the subscale reflecting resources for having a worker role, where a linear trend was found despite a $p$-value just above 0.05 according to the Kruskal-Wallis test. The group with recent immigrants showed the highest rating, followed by the young with psychosis. The group with a history of SUD rated their prospects at lower levels than these two groups.

\subsection{Everyday activities}

There was a statistically significant difference between the groups regarding their satisfaction with the everyday activities they performed. The young with psychosis rated a higher level of satisfaction than the other two groups, who did not differ from each other. There was a linear trend for activity level, where the group of immigrants scored the highest, the young with psychosis formed the middle group, and those with a history of SUD scored the lowest.

\subsection{Well-being}

A linear trend was also found for the quality of life index (see Table 3). The young with psychosis scored the highest, those with substance use formed the middle group, and the immigrant group scored the lowest. No group differences appeared on the overall life satisfaction.

\subsection{Level of functioning}

The recent immigrants were the highest rated group on psychosocial functioning (see Table 3). They were rated as better functioning by the research assistant than the young with psychosis, who in turn were rated as better functioning than the group with a history of SUD. Those with a history of SUD were rated the highest concerning symptom severity, thus having the least severe symptoms, whereas there was no difference between the two other groups. 


\section{Discussion}

This study aimed to explore differences and similarities regarding work-related and associated factors among three groups with mental disorders with different additional difficult life situations, the variety of which seemed to generate varying consequences.

Those who had a history of SUD showed the most detrimental situation in relation to work/studies and the worker role. They scored lower than the other groups on recent work/study experience and satisfaction with that experience and formed the middle group, after the recent immigrants, regarding resources for engaging in a worker role. Considering that this group had the best circumstances regarding educational level in the current study and least severe psychiatric symptoms according to the research assistant's assessment, one can speculate that a history of SUD impacts greatly in relation to work and employment. The fact that this is a problematical area for people with SUD is evident in the literature, and several recent research projects have attempted to find predictors and support measures to enhance successful work outcome [38-40]. The most prominent finding seems to be that individual placement and support (IPS) [41] and recovery centers [39] are promising work-oriented support alternatives for people with SUD.

The young with psychosis appeared to have a mid-position regarding how they rated their work experiences and satisfaction with the same, but they showed the lowest ratings in terms of resources for having a worker role, where a linear trend was found between the groups. This is in line with previous research on young people with psychosis, found to be disadvantaged in relation to career development since the early onset of psychosis tends to interrupt higher education and entrance to the labor market $[8,9]$. The young with psychosis were more satisfied, however, with their everyday activities in general and with their quality of life. Moreover, younger age in general, across the three groups, was associated with better quality of life. These are untypical findings; older age is generally related with better quality of life in different diagnostic groups with mental illness [42]. The young people with psychosis who participated in this study may possibly have received qualified support from the mental health care services, including early detection and intervention, which may have positively influenced their satisfaction with everyday life. Nevertheless, the current quality of life results indicate that a history of SUD and recent immigration interacted negatively with mental illness, more so than having developed psychosis at a young age and risking an interrupted work/study career. The reasons for this cannot, however, be explained in the current study.

The recent immigrants formed the group with highest prevalence of recent work/study experiences. This must be seen in relation to the educational and other activities offered in the PTSD center, which may have been perceived as work or studies. However, they scored highest on resources for having a worker role, according to the test of a linear trend, which indicates they would have experiences from open-market employment in their countries of origin. They were also the group with highest current level of activity and the highest level of psychosocial functioning. They were low on satisfaction with their everyday activities, however, and on a par with the group with a history of SUD, and their symptom severity was on a par with the young people with psychosis and worse than the SUD group. They were also the least satisfied group according to the quality of life index. Their low levels of satisfaction, seen against their high prevalence of work experiences and high self-ratings of work capacity, may be due to under-utilization of their work resources. A study on foreign-born workers in Sweden showed that a mismatch between education and type of work was related with poor self-ratings of health [43]. The pattern of findings regarding this group indicates comparatively good prerequisites for employment in terms of work experience and worker role capacities. The identified dissatisfaction with current life situation and severe psychiatric symptoms would be the main issues with respect to employment in this group. The findings could be seen as reactions to unused resources, but may also be interpreted to be in line with research suggesting that treatment for PTSD may improve mentally ill clients' ability to benefit from supported employment [44]. The latter [41], as well as supported education [45], has otherwise been found effective for service users with PTSD, but those findings were based on war veterans. Research on supported employment with immigrants is scarce and inconclusive [46].

When considering how to assist the three groups regarding access to work and employment, it is apparent from the results of this study that they would need different pathways. The group of young people with psychosis lacked higher education, and supported education would be a possible alternative for them, while building on their assets in terms of positive views of a future worker role and beliefs in one's 
resources. They would also benefit from long-term highly available and continuous psychosocial support as found by Stralin and colleagues [11]. Those with a history of SUD seemed to have a very low belief in themselves in relation to work and employment and a dissatisfying life situation. Such experiences may be reinforced by negative attitudes among employers and workmates [47]. This indicates that they would need a broad array of support, including supported employment but possibly also support that may promote activity balance and quality of life, for example an activity-based lifestyle intervention [48]. The group of people who had recently immigrated had good resources in terms of work experiences and beliefs in a future worker role. Based on both the current findings and previous research [44], they would, however, need support in relation to the low level of their satisfaction with life and their psychiatric symptoms to access their work-related resources.

The three groups also showed some similarities. There was no difference between them with respect to beliefs in a future worker role. Their rating on this variable was very low, corresponding to a mean on each item around 1.9 on the five-point scale, compared to people on long-term sick leave who had a mean score per item of 4.2 [49]. These very low aspirations regarding a future worker role are saddening, particularly since research shows that people with disabilities are an underutilized resource that would be of great value to society [50]. Moreover, first-person reports indicate that working or not working has a conditioning nature; i.e., those who work tend to be satisfied with that and want to carry on working, and those who have no employment adjust to that condition and increasingly appreciate it over time [14]. The groups were also low on general life satisfaction, which may be a result of their pessimistic view of having a worker role in the future. Research consistently shows that people with employment are more satisfied with their lives compared to those without, and this goes for people in general, not only those with mental illness. Including people with mental illness in the labor force would thus benefit both society and the individual.

No gender differences appeared on any of the investigated variables, which is noteworthy as some research shows, for example, that women with mental illness rate their quality of life at a lower level than men do [51]. Although no study reporting worse quality of life for men could be found, there is also research that indicates an absence of gender differences [42]. Research on people with mental illness in terms of their everyday activities suggests that women tend to have a more favorable situation than men [52]. The fact that no gender differences appeared in the current study suggests that other factors, possibly the additional difficult life situations, played a more important role than gender for the variation in the variables addressed.

\subsection{Limitations}

Women were in a minority in this study, but amounted to approximately $30 \%$ of the total sample, which is the proportion considered sufficient not to undermine statistical power when comparing two groups [35]. The lack of gender differences would thus not be due to a methodological drawback. The convenience sampling employed in this study constitutes, however, a weakness. Systematic sampling to ensure similarities on non-experimental variables was made difficult, since the three groups received their services in different support systems. Furthermore, it was not possible to recruit the number of participants indicated by the power analysis, entailing a risk of Type- 2 errors. These circumstance limit both the internal and the external validity of the study. It was a strength, however, that we were able to recruit samples representing three groups of great societal relevance in most western countries. Moreover, meticulous data collection was ensured by careful training and calibration of the research assistants. However, the findings must be interpreted with some caution and should not be generalized to other settings or other groups with mental illness at risk of stigma. Comorbidity of physical illness, ageing with mental illness or losing one's job at an older age are examples of other vulnerable situations. Thus, the choice of the particular three groups for the current study was not self-evident. Although based on relevance in relation to the societal discourse and policies pertaining to health care and support systems in Sweden, other subgroups of people with mental illness deserve attention as well and should be in focus in future research.

\subsection{Conclusion}

This study illustrated how a difficult life situation - due to mental illness and another vulnerability in terms of developing psychosis in young age, having a history of SUD, or having recently immigrated - covaried with work and employment factors. The three studied groups appeared to experience quite varying 
consequences of the respective difficulty that added to their mental illness. Each group presented a unique set of assets and limitations with respect to work and employment, suggesting that they also need unique support measures to identify and utilize their assets and resources. It is hoped that the findings from this study may stimulate to further study of multiple possibly stigmatizing factors in relation to mental illness and work. In particular, the current general picture on a group level needs to be supplemented with qualitative, in-depth research.

\section{Acknowledgments}

The authors gratefully acknowledge that the Swedish Research Council for Health, Working Life, and Welfare (FORTE) financially supported this study (Reg. No. 2014-4732).

\section{Conflict of interest}

None to report.

\section{References}

[1] Burns T, Catty J, Becker T, Drake RE, Fioritti A, Knapp M, Lauber C, Rossler W, Tomov T, van Busschbach J, White G, Wiersma, D. The effectiveness of supported employment for people with severe mental illness: a randomised controlled trial. Lancet. 2007;370(9593):1146-52.

[2] Witt K, Milner A, Chastang JF, LaMontagne AD, Niedhammer I. Impact of lifetime compared to adolescent-onset mental illness on psychosocial employment quality in adulthood: analysis of a nationally representative French cohort. Int Arch Occup Environ Health. 2018;91(7):887-900.

[3] Laws J. 'Recovery work' and 'magic' among long-term mental health service-users. Sociol Rev. 2013;61(2):344-62.

[4] Lexen A, Hofgren C, Bejerholm U. Reclaiming the worker role: perceptions of people with mental illness participating in IPS. Scand J Occup Ther. 2013;20(1):54-63.

[5] Bejerholm U, Areberg C, Hofgren C, Sandlund M, Rinaldi M. Individual placement and support in Sweden - a randomized controlled trial. Nord J Psychiatry. 2015;69(1):57-66.

[6] Shaw LR, Chan F, McMahon BT. Intersectionality and disability harassment: The interactive effects of disability, race, age, and gender. Rehabil Couns Bull. 2012;55(1):82-91.

[7] Thornicroft G, Rose D, Kassam A, Sartorius N. Stigma: ignorance, prejudice or discrimination? Br J Psychiatry. 2007;190:192-3.

[8] Cotter J, Lin A, Drake RJ, Thompson A, Nelson B, McGorry $P$, Wood SJ, Yung AR. Long-term employment among people at ultra-high risk for psychosis. Schizophr Res. 2017184:26-31.

[9] Tognin S, Grady L, Ventura S, Valmaggia L, Sear V, McGuire P, Fusar-Poli P, Spencer TJ. The provision of education and employment support at the Outreach and Support in South London (OASIS) service for people at clinical high risk for psychosis. Front Psychiatry. 2019;10:799.

[10] Bassett J, Lloyd C, Bassett G. Work issues for young people with psychosis: Barriers to employment. Br J Occup Ther 2001;64(2):66-72.

[11] Stralin P, Skott M, Cullberg J. Early recovery and employment outcome 13 years after first episode psychosis. Psychiatry Res. 2019;271:374-80.

[12] Conway KP, Compton W, Stinson FS, Grant BF. Lifetime comorbidity of DSM-IV mood and anxiety disorders and specific drug use disorders: results from the National Epidemiologic Survey on Alcohol and Related Conditions. J Clin Psychiatry. 2006;67(2):247-57.

[13] Schuckit MA. Comorbidity between substance use disorders and psychiatric conditions. Addiction. 2006;101(Suppl 1):76-88.

[14] Strickler DC, Whitley R, Becker DR, Drake RE. First person accounts of long-term employment activity among people with dual diagnosis. Psychiatr Rehabil J. 2009;32(4):261-8.

[15] Tinghog P, Al-Saffar S, Carstensen J, Nordenfelt L. The association of immigrant- and non-immigrant-specific factors with mental ill health among immigrants in Sweden. Int J Soc Psychiatry. 2010;56(1):74-93.

[16] Pooremamali P, Eklund M, Ostman M, Persson D. Muslim Middle Eastern clients' reflections on their relationship with their occupational therapists in mental health care. Scand J Occup Ther. 2012;19(4):328-40.

[17] Pooremamali P, Persson D, Östman M, Eklund M. Facing the challenges during rehabilitation - Middle Eastern immigrants' paths to occupational well-being in Sweden. J Occup Sci. 2015;22(2):228-41.

[18] Argentzell E, Hakansson C, Eklund M. Experience of meaning in everyday occupations among unemployed people with severe mental illness. Scand J Occup Ther. 2012;19(1): 49-58.

[19] Beagan B, Saunders S. Occupations of masculinity: Producing gender through what men do and don't do. J Occup Sci. 2005;12(3):161-9.

[20] Eklund M, Sandlund M. Work experiences among attendees of day centres for people with psychiatric disabilities. Work. 2015;53(2):377-85.

[21] Eklund L, Eklund M. Doing or undoing gender? An explorative study of gender, activities and well-being among people with mental illness attending day centers in Sweden. Soc Ment Health. 2015;5(3):218-33.

[22] Leufstadius C, Gunnarsson AB, Eklund M. Meaningfulness in day centers for people with psychiatric disabilities - Gender and empowerment aspects. Occup Ther Ment Health. 2014;30(2):178-95.

[23] WHO. The ICD-10 classification of mental and behavioural disorders. Geneva: World Health Organization; 1993.

[24] Eklund M, Sandlund M. The life situation of people with persistent mental illness visiting day centers: A comparative study. Community Ment Health J. 2012;48(5):592-7.

[25] Wastberg BA, Haglund L, Eklund M. Psychometric properties of the Worker Role Self-assessment instrument used to evaluate unemployed people in Sweden. Scand J Occup Ther. 2009;16(4):238-46.

[26] Eklund M, Backstrom M. Factor structure and construct validity of the Worker Role Self-assessment (WRS) when used for people with psychiatric disabilities in Sweden. Eval Health Prof. 2016;39(3):299-316.

[27] Eklund M. Satisfaction with Daily Occupations - A tool for client evaluation in mental health care. Scand J Occup Ther. 2004;11(3):136-42. 
[28] Eklund M, Backstrom M, Eakman A. Psychometric properties and factor structure of the 13-item satisfaction with daily occupations scale when used with people with mental health problems. Health Quality Life Outc. 2014;12(1):7.

[29] Eklund M, Gunnarsson AB. Satisfaction with Daily Occupations (SDO): Construct validity and test-retest reliability of a screening tool for people with mental disorders. Aust Occup Ther J. 2007;54(1):59-65.

[30] Priebe S, Huxley P, Knight S, Evans S. Application and results of the Manchester Short Assessment of Quality of Life (MANSA). Int J Soc Psychiatry. 1999;45(1):7-12.

[31] Björkman T, Svensson B. Quality of life in people with severe mental illness. Reliability and validity of the Manchester Short Assessment of Quality of Life (MANSA). Nord J Psychiatry. 2005;59(4):302-6.

[32] Endicott J, Spitzer RL, Fleiss JL, Cohen J. The global assessment scale. A procedure for measuring overall severity of psychiatric disturbance. Arch Gen Psychiatry. 1976; 33(6):766-71.

[33] Startup M, Jackson MC, Bendix S. The concurrent validity of the Global Assessment of Functioning (GAF). Br J Clin Psychol. 2002;41(4):417-22.

[34] Vatnaland T, Vatnaland J, Friis S, Opjordsmoen S. Are GAF scores reliable in routine clinical use? Acta Psychiatr Scand. 2007;115(4):326-30.

[35] Altman DG. Practical statistics for medical research. London: Chapman \& Hall; 1993.

[36] Cohen J. Statistical power analysis for the behavioral sciences. Hillsdale NJ: Lawrence Erlbaum; 1988.

[37] IBM SPSS Statistics 26 core system user's guide [ftp:// public.dhe.ibm.com/software/analytics/spss/documentati on/statistics/26.0/en/client/Manuals/IBM_SPSS_Statistics_ Core_System_User_Guide.pdf]

[38] Sahker E, Ali SR, Arndt S. Employment recovery capital in the treatment of substance use disorders: Six-month follow-up observations. Drug Alcohol Depend. 2019;205: 107624.

[39] Kelly JF, Stout RL, Jason LA, Fallah-Sohy N, Hoffman LA, Hoeppner BB. One-stop shopping for recovery: An investigation of participant characteristics and benefits derived from U.S. Recovery Community Centers. Alcohol Clin Exp Res. 2020.

[40] Harrison J, Krieger MJ, Johnson HA. Review of Individual Placement and Support employment intervention for persons with substance use disorder. Subst Use Misuse. 2020;55(4):636-43.
[41] Bond GR, Drake RE, Pogue JA. Expanding Individual Placement and Support to populations with conditions and disorders other than serious mental illness. Psychiatr Serv. 2019;70(6):488-98.

[42] Priebe S, Reininghaus U, McCabe R, Burns T, Eklund M, Hansson L, Junghan U, Kallert T, van Nieuwenhuizen C, Ruggeri M, Slade M, Wand D. Factors influencing subjective quality of life in patients with schizophrenia and other mental disorders: a pooled analysis. Schizophr Res. 2010;121(1-3):251-8.

[43] Dunlavy AC, Garcy AM, Rostila M. Educational mismatch and health status among foreign-born workers in Sweden. Soc Sci Med. 2016;154:36-44.

[44] Mueser KT, Essock SM, Haines M, Wolfe R, Xie H. Posttraumatic stress disorder, supported employment, and outcomes in people with severe mental illness. CNS Spectr. 2004;9(12):913-25.

[45] Ellison ML, Reilly ED, Mueller L, Schultz MR, Drebing CE. A supported education service pilot for returning veterans with posttraumatic stress disorder. Psychol Serv. 2018;15(2):200-7.

[46] Strom V, Scheel I, Dalsbo TK, Kirkehei I. In: Effect of active labor market programs for immigrants. edn. Oslo, Norway; 2015.

[47] Jansson I, Gunnarsson AB. Employers' views of the impact of mental health problems on the ability to work. Work. 2018;59(4):585-98.

[48] Eklund M, Tjornstrand C, Sandlund M, Argentzell E. Effectiveness of Balancing Everyday Life (BEL) versus standard occupational therapy for activity engagement and functioning among people with mental illness - a cluster RCT study. BMC Psychiatry. 2017;17(1):363.

[49] Eklund M, Wastberg BA, Erlandsson LK. Work outcomes and their predictors in the Redesigning Daily Occupations (ReDO) rehabilitation programme for women with stressrelated disorders. Aust Occup Ther J. 2013;60(2):85-92.

[50] Lengnick-Hall ML, Gaunt PM, Kulkarni M. Overlooked and underutilized: People with disabilities are an untapped human resource. Hum Resour Manage. 2008;47(2):255-73.

[51] Colillas-Malet E, Prat G, Espelt A, Juvinya D. Gender differences in health-related quality of life in people with severe mental illness. PLoS One. 2020;15(2):e0229236.

[52] Eklund M, Eklund L. Gender in relation to work motivation, satisfaction and use of day center services among people with psychiatric disabilities Scand J Occup Ther. 2017; 24(3):214-21. 